\title{
NOTE
}

\section{Phase Separation in Non-aqueous Dispersions Containing Polymer Molecules and Colloidal Spheres}

Recently one of us (1) predicted on theoretical grounds that the phenomenon of incompatibility, well known in mixtures of two polymers in the same solvent $(2-6)$, could also take place in mixtures of different types of colloidal particles. On the basis of liquid state theories applied to colloidal systems, it was expected that a system containing sterically stabilized particles and polymer molecules could show phase separation, depending on the molar mass and the concentration of the polymer.

Two effects were considered: (a) polymer molecules lose configurational entropy when they penetrate the space between particle surfaces in close proximity (volume restriction); (b) segments of (added) polymer molecules will interact with segments of polymer chains attached to the particle surface (osmotic effect). Both effects will promote the expulsion of added polymer from the space between the particles, when the solvent is not too poor. This leads to an effective attraction between the particles. Recently we found that mechanism (a) was proposed already some 20-25 years ago by Oosawa and Asakura $(7,8)$. The scant experimental evidence on this subject (8-10) indeed suggests that the predictions are qualitatively correct.

In this note we present some experiments on lyophilized silica spheres dispersed in cyclohexane containing polystyrene at $34^{\circ} \mathrm{C}$.

\section{MATERIALS}

Lyophilic, spherical, monodisperse silica particles were prepared in two steps according to (modified) methods described in the literature $(12,13)$. More details concerning the preparation technique will be given in a forthcoming paper. The silica particles are covered with a dense layer of stearyl alcohol chains, chemically bonded to the surface. The stable dispersion in cyclohexane was characterized by light-scattering fluctuation spectroscopy. The measurements were performed with a laboratory-built instrument. A Spectra Physics model 165 Ar-ion laser was used (514,5 nm) and the light was detected with an EMT 9558 photon multiplier. The correlation function was determined with a Saicor Honeywell 42A correlator. From the diffusion coefficient the hydrodynamic radius of the particles was found to be $21 \mathrm{~nm}$. The standard deviation as assessed from Electron Microscopy was $15 \%$. Conventional light scattering carried out with a Fica 50 instrument (Société Francaise d'Instruments de Controle et d'Analyse) equipped with a Philips CS $100 \mathrm{~W} / \mathrm{Z}$ mercury arc lamp showed the absence of clusters.

Five different polystyrene samples (PS) were used. The higher molar mass samples were obtained from Pressure Chemical Company (batches $1 \mathrm{c}$ and 14b). The mass averaged molar masses, MW, are reported to be $1.94 \times 10^{5}$ (PS IV) and 2.4 $\times 10^{6}$ (PS V) $\mathrm{g} \mathrm{mol}^{-1}(6)$. Samples with lower MW were prepared in our laboratory by anionic polymerization in toluene-tetrahydrofuran (1000:1), using $n$-butyllithium (Merck) as initiator. The polymerization was carried out under nitrogen at $45^{\circ} \mathrm{C}$. Standard

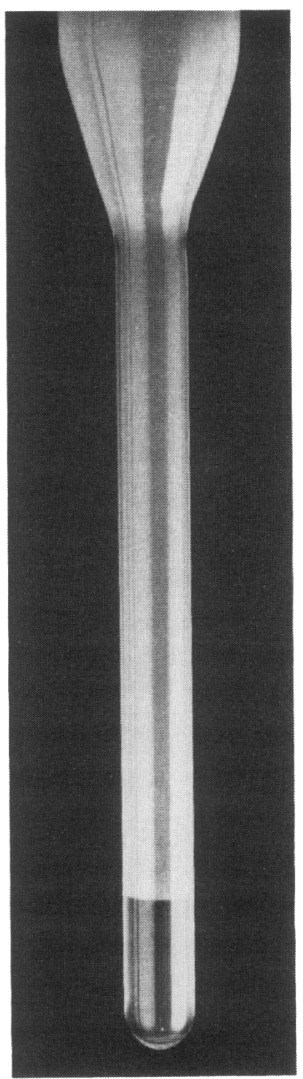

FIG. 1. Phase separation in a mixture of PS sample $\mathrm{V}$ and silica in cyclohexane (cooled below $34^{\circ} \mathrm{C}$ ). 
TABLE I

Limiting Phase Separation Concentrations of Polystyrene of Several (Mass Averaged) Molar Masses

\begin{tabular}{clllll}
\hline PS sample & I & II & III & IV & V \\
\hline $\mathrm{MW} / 10^{3} \mathrm{~g} \mathrm{~mol}^{-1}$ & 8 & 36 & 130 & 194 & 2400 \\
$C_{\text {lim }} / \mathrm{g} \mathrm{dm}^{-3}$ & $82 \pm 1$ & $48 \pm 1$ & $35 \pm 1$ & $31 \pm 1$ & $17 \pm 1$ \\
$\frac{C_{\lim } / \mathrm{g} \mathrm{dm}^{-3}}{\left(\mathrm{MW} / \mathrm{g} \mathrm{mol}^{-1}\right)^{-1 / 4}}$ & $7.8 \times 10^{2}$ & $6.6 \times 10^{2}$ & $6.6 \times 10^{2}$ & $6.5 \times 10^{2}$ & $6.7 \times 10^{2}$ \\
\hline
\end{tabular}

procedures were used for the purification of the monomer and the solvent (14). Molar masses (MW) were determined by light scattering in toluene, using pure benzene as a scattering standard $\left(R_{\theta}=15.9 \times 10^{-6}\right.$ $\mathrm{cm}^{-1}$ at $\lambda_{0}=546 \mathrm{~nm}$ ) and were found to be $8 \times 10^{3}$, $36 \times 10^{3}, 13 \times 10^{4} \mathrm{~g} \mathrm{~mol}^{-1}$.

\section{METHODS}

Test solutions of PS and lyophilic silica in cyclohexane were prepared by mixing appropriate amounts of a stock solution of PS (the PS content was determined by drying at $80^{\circ} \mathrm{C}$ until constant weight) and pure cyclohexane in a specially shaped test tube (Fig. 1). To $5 \mathrm{~cm}^{3}$ of this solution was added $0.2 \mathrm{~cm}^{3}$ of a $26 \%(w / v)$ dispersion of silica in cyclohexane, yielding a silica concentration of $1 \%(\mathrm{w} / \mathrm{v})$. The solution was thoroughly mixed and the test tube was tightly stoppered to prevent evaporation. The solutions were allowed to stand at $34^{\circ} \mathrm{C}$ and were visually inspected at intervals from 0.25 to $24 \mathrm{hr}$.

\section{RESULTS}

Upon mixing the transparent solutions of PS and silica, mixtures with a polymer concentration above a certain limiting value (defined below) became turbid. Within $1 \mathrm{hr}$ two translucent liquid phases could be distinguished separated by a sharp but sometimes hardly visible interface. The volume of the lower phase initially increased with time but after $24 \mathrm{hr}$ no significant changes could be observed. The "limiting phase separation concentration," $C_{\text {lim }}$, of the PS, defined as the concentration below which no phase separation could be observed $24 \mathrm{hr}$ after mixing, was determined for the five PS samples used. The results are summarized in Table I. Obviously $C_{\text {lim }}$ depends on $\mathrm{MW}$ of the polymer, apparently with a power $1 / 4$.

At polymer concentrations from 1 to 1.5 times $C_{\text {lim }}$ the volume of the lower phase increased with the polymer concentration. At higher concentrations the volume remained constant. This final volume did not vary significantly with MW (ca. $0.1 \mathrm{~cm}^{3}$ ) except for the highest MW (ca. $0.3 \mathrm{~cm}^{3}$ ). It could be established that the smaller lower phase contained most of the silica and almost no PS. On cooling below $34^{\circ} \mathrm{C}$ (theta conditions) the upper phase became milky white, because of the insolubility of PS in cyclohexane under these conditions (Fig. 1). The lower phase only showed a slight turbidity with the highest MW.

The phase separation proved to be reversible, as the two phases readily mixed by gentle agitation. Only with the lowest MW a gel-like lower phase was obtained. The boundary between the two phases was very sharp, however, and not quite rigid. The same phenomenon occured with the PS sample II at high concentrations after an aging period of several days.

\section{DISCUSSION}

It is clear that our experimental findings cannot be explained by assuming physical adsorption of PS onto the lyophilic silica surface. This phenomenon would result in the formation of loose flocs at very small polymer concentrations. At higher concentrations enhanced stabilization is expected (15). In our experiments however, phase separation occurs only above a certain polymer concentration. Moreover, the silica-rich layer is in general a fluid phase, readily miscible with the upper layer. Physical adsorption of PS is not probable as the silica surface is coated with an aliphatic layer, a "nonsolvent" for polystyrene.

We believe that the phase separation is caused by volume restriction, i.e., by a reduction of the number of configurations of the polymer molecules near the particle surfaces. This drives the particles to a separate phase containing much less polymer. It can be shown (1) that this effect is larger for a polymer with a larger chain length, although it is not yet possible to explain the power $1 / 4$ quantitatively.

Further research, including other solvents, is in progress and will be published in due time.

\section{ACKNOWLEDGMENTS}

We are indebted to Mr. J. W. Jansen who prepared the silica, to Mr. H. J. Mos who carried out the lightscattering fluctuation experiments, and to Mr. W. A. 
den Hartog for the photograph. This work was part of the research program of the Netherlands Foundation for Chemical Research (SON) and was carried out with financial aid from the Netherlands Organization for Advancement of Pure Research (ZWO).

\section{REFERENCES}

1. Vrij, A., Pure Appl. Chem. 48, 471 (1976).

2. Dobry, A., and Boyer-Kawenoki, F., J. Polym. Sci. 2, 90 (1947).

3. Kern, R. J., and Slocombe, R. J., J. Polym. Sci. 15, 183 (1955).

4. Scott, R. L., J. Chem. Phys. 17, 279 (1949).

5. Tompa, H., Trans. Faraday Soc. 45, 1142 (1949).

6. (a) Van den Esker, M. W. J., and Vrij, A., J. Polym. Sci., Polym. Phys. Ed. 14, 1943 (1976); (b) Van den Esker, M. W. J., Laven, J., Broeckman, A., and Vrij, A., J. Polym. Sci., Polym. Phys. Ed. 14, 1953 (1976); (c) Van den Esker, M. W. J., and Vrij, A., J. Polym. Sci., Polym. Phys. Ed. 14, 1967 (1976).

7. Asakura, S., and Oosawa, F., J. Chem. Phys. 22, 1255 (1954).
8. Asakura, S., and Oosawa, F., J. Polym. Sci. 33, 183 (1958).

9. Vester, C. F., Kolloid Z. 84, 63 (1938).

10. Sieglaff, C. L., J. Polym. Sci. 41, 319 (1959).

11. Li-In-On, F. K. R., Vincent, B., and Waite, F. A., ACS Symposium Series No. 19 (K. L. Mittal, Ed.) (1975).

12. Stöber, W., Fink, A., and Bohn, E., J. Colloid Interface Sci. 26, 62 (1968).

13. Iler, R. K., US Patent 2,801,185 (1957).

14. Hoen, N. G. M., Thesis, Chemistry Department, Eindhaven University of Technology (1977).

15. Fischer, E. W., Kolloid Z. 160, 120 (1958).

H. DE HEK

A. VRIJ

Van't Hoff Laboratory for Physical and Colloid Chemistry

State University of Utrecht

Transitorium III, Padualaan 8

Utrecht, The Netherlands

Received January 11, 1979; accepted January 18, 1979 